Jurnal Media Agribisnis Vol. 3 No. 1 Tahun 2018 Hal 1 - 11

Media Komunikasi Hasil Penelitian Bidang Ilmu Agribisnis ISSN print 2587-7027

ISSN online 2541-6898

\title{
FAKTOR-FAKTOR YANG MEMPENGARUHI PENERIMAAN PETANI KARET (Hevea Brasiliensis) DI DESA BARU KECAMATAN MESTONG KABUPATEN MUARO JAMBI
}

\author{
Pariyanto $^{1)}$, Rizki Gemala Busyra ${ }^{2)}$ \\ ${ }^{1)}$ Alumni Program Studi Agribisnis Fakultas Pertanian Universitas Batanghari \\ ${ }^{2)}$ Program Studi Agribisnis, Fakultas Pertanian Universitas Batanghari \\ J1. Slamet Riyadi, Broni Jambi. 36122. Telp. +62074160103 \\ ${ }^{2)}$ Email korespondensi : rizkigb1983@gmail.com
}

\begin{abstract}
This research was conducted in June 2017 at Baru Village of Mestong Subdistrict of Muaro Jambi Regency.The purpose of this research is to know the description of the revenue of rubber farmer, and the influence of independent variables (Rubber Production, Price, Plant Age, Education Level, Types of Seeds, and Tapping Technique) to the revenue of rubber farmers. The research used survey method,completed by Random sampling design with 64 farmers as a sample or $15 \%$ of the population (427 farmers).

The analysis used descriptive method and multiple regression. The result showed that the average of rubber farmerrevenue in this research was Rp.87.453,95 / Ha / Period and simultaneously independent variables give significant influence to the farmer revenue. While partially, rubber production, seed type, and tapping technique hadsignificant effect to the farmer's revenue, while rubber price, age of plant, and education level did not have significantly influence to revenue of rubber farmer.
\end{abstract}

Keywords : Rubber, Revenue, Factor, Influence

\begin{abstract}
Abstrak
Penelitian ini dilaksanakan di Desa Baru Kecamatan Mestong Kabupaten Muaro Jambi.Penelitian dilaksanakan bulan Juni 2017.Tujuan penelitian untuk mengetahui gambaran penerimaan usahatani karet, dan pengaruh variabel bebas (Produksi Karet, Harga, Umur Tanaman, Tingkat Pendidikan, Jenis Bibit, dan Teknik Penyadapan) terhadap penerimaan petani karet.Metode penelitian adalah menggunakan metode survey.Teknik pengambilan sampel secara acak (random sampling) dengan jumlah sampel 64 rumah tangga petani (Petani) atau sebesar $15 \%$ dari populasi (427 Petani).

Alat analisis menggunakan metode deskriptif uji regresi linier berganda.Hasil penelitian menunjukan rata-rata penerimaan usahatani karet di daerah penelitian adalah Rp.87.453,95/Ha/Sadapdan secara simultan variabel-variabel bebas memberikan pengaruh secara nyata terhadap penerimaan petani.Sedangkan secara parsial produksi karet, jenis bibit, dan teknik penyadapan berpengaruh nyata terhadap penerimaan petani, sedangkan harga karet, umur tanamam, dan tingkat pendidikan tidak berpengaruh secara nyata terhadap penerimaan petani karet.
\end{abstract}

Kata Kunci : Karet, Penerimaan, Faktor, Pengaruh 
Jurnal Media Agribisnis Vol. 3 No. 1 Tahun 2018 Hal 1 - 11

Media Komunikasi Hasil Penelitian Bidang Ilmu Agribisnis

ISSN print 2587-7027

ISSN online 2541-6898

\section{PENDAHULUAN}

Agribisnis yang merupakan suatu rangkaian sistem usaha berbasis pertanian harus mendapat perhatian penuh untuk mengembangkan sektor pertanian.Usaha perkebunan karet di Provinsi Jambi dari tahun ke tahun mengalami perkembangan luas lahan maupun produksi yang cukup signifikan.Dapat dilihat pada Tabel 1. Berdasarkan Tabel 1, dapat dilihat bahwa Kabupaten Muaro Jambi dengan produktivitas tertinggi yaitu 0,62Ton/Ha.

Produksi tanaman karet di Kabupaten Muaro Jambi menurut Kecamatan pada tahun 2015.Berdasarkan Tabel 2 dapat dilihat bahwa Kecamatan Mestong mempunyai luas tanam 14.597 Ha.yang merupakan luas tanam terluas kedua setelah Kecamatan Sekernan. Serta mempunyai produktifitas tertinggi yaitu sebesar 0,694Ton/Ha.

Kecamatan Mestong terdiri dari 14 desa,dan tingkat produktifitas tanaman karet yang berbeda-beda.Untuk lebih jelasnya dapat dilihat pada Tabel 3.

Berdasarkan Tabel 3 dapat dilihat mempunyai luas areal tanaman karet terluas yaitu sebesar $1.486 \mathrm{Ha}$, namun mempunyai produktifitas terendah dari desa lainnya yaitu 0,48 Ton/Ha.

Tabel 1. Luas Areal, Produksi, Dan Produktivitas Tanaman Karet Di Kabupaten Yang Ada Di Provinsi Jambi Tahun 2015.

\begin{tabular}{clrcc}
\hline No. & Kabupaten/ Kota & $\begin{array}{c}\text { Luas Areal } \\
(\mathrm{Ha})\end{array}$ & $\begin{array}{c}\text { Produksi } \\
(\mathrm{Ton})\end{array}$ & $\begin{array}{c}\text { Produktivitas } \\
(\mathrm{Ton} / \mathrm{Ha})\end{array}$ \\
\hline 1. & Batangsadap & 113.398 & 69.368 & 0,61 \\
2. & Muaro Jambi & $\mathbf{5 8 . 4 5 4}$ & $\mathbf{3 6 . 3 4 5}$ & $\mathbf{0 , 6 2}$ \\
3. & Bungo & 101.328 & 45.337 & 0,45 \\
4. & Tebo & 114.054 & 50.694 & 0,44 \\
5. & Merangin & 132.053 & 61.758 & 0,47 \\
6. & Sarolangun & 125.213 & 58.394 & 0,47 \\
7. & Tanjung Jabung & 14.806 & 6.570 & 0,44 \\
& Barat & & & \\
8. & Tanjung Jabung & 7.763 & 2.852 & 0,37 \\
& Timur & & & \\
9. & Kerinci & 1.850 & 345 & 0,19 \\
10. & Kota Sungai Penuh & - & - & - \\
11. & Kota Jambi & - & - & 0,49 \\
\hline & Jumlah & 668.919 & 331.663 & - \\
\hline & Rata-rata & $60.810,82$ & $30.151,18$ & \\
\hline
\end{tabular}

Sumber : Dinas Perkebunan Provinsi Jambi, 2016 
Jurnal Media Agribisnis Vol. 3 No. 1 Tahun 2018 Hal 1 - 11

Media Komunikasi Hasil Penelitian Bidang Ilmu Agribisnis ISSN print 2587-7027

ISSN online 2541-6898

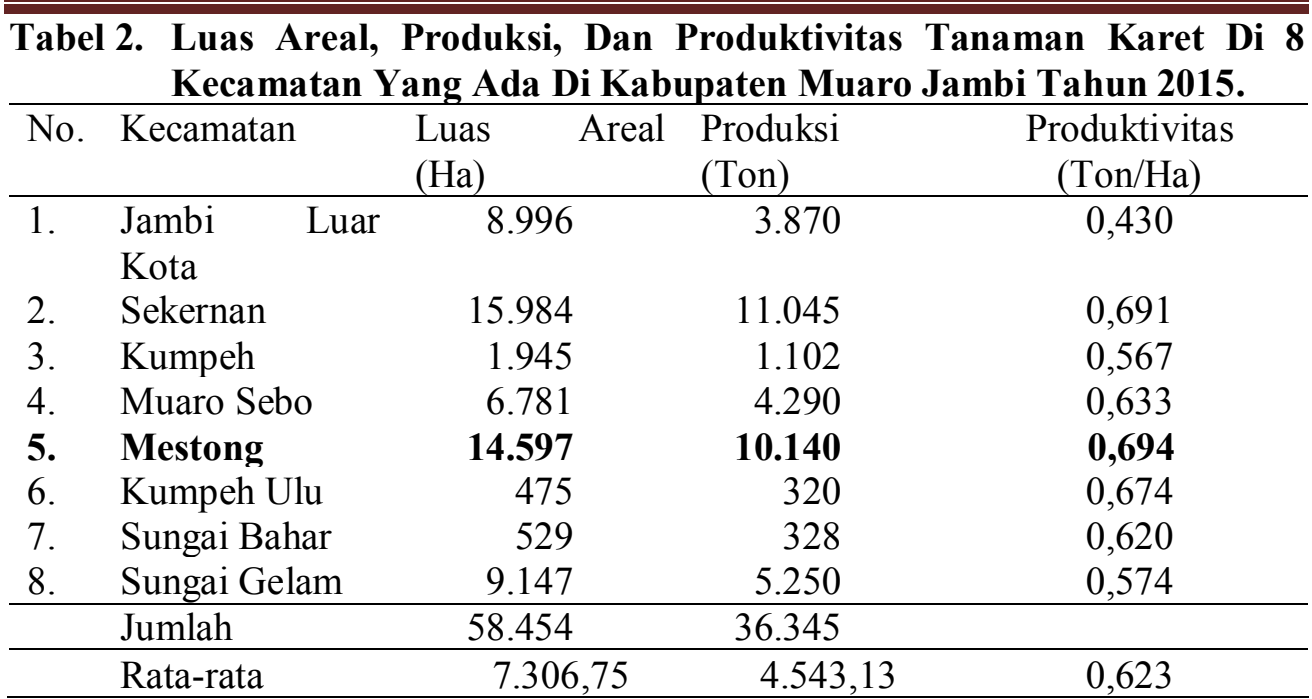

Sumber : Dinas Perkebunan Provinsi Jambi, 2016

Untuk meningkatkan produksi karet yang akhirnya dapat meningkatkan penerimaan petani karet di Desa Baru dapat dipengaruhi oleh berbagai macaminput diantaranya produksi karet, harga karet, tingkat pendidikan,umur tanaman karet, jenis bibit karet yang digunakan, dan teknik penyadapan.

Tabel 3. Luas Area, Produksi, Dan Produktifitas Tanaman Karet Di 14 DesaYang Ada Di Kecamatan Mestong Tahun 2015.

\begin{tabular}{llccc}
\hline No. & Desa & Luas Areal (Ha) & Produksi (Ton) & $\begin{array}{c}\text { Produktivitas } \\
\text { (Ton/Ha) }\end{array}$ \\
\hline 1. & Pondok Meja & $1.264,247$ & 844 & 0,67 \\
2. & Sebapo & $1.021,056$ & 763 & 0,75 \\
3. & Muaro Sebapo & 842,640 & 655 & 0,78 \\
4. & Tempino & 860,738 & 676 & 0,79 \\
5. & Naga Sari & 854 & 716 & 0,84 \\
6. & Pelempang & 1.070 & 746 & 0,70 \\
7. & Desa Baru & $\mathbf{1 . 4 8 6}$ & $\mathbf{7 0 7}$ & $\mathbf{0 , 4 8}$ \\
8. & Tanjung Pauh 32 & 884,121 & 665 & 0,75 \\
9. & Tanjung Pauh 39 & 720,990 & 548 & 0,76 \\
10. & Nyogan & $1.268,514$ & 844 & 0,67 \\
11. & Sungai Landai & 1.258 & 831 & 0,66 \\
12. & Ibru & $1.227,167$ & 832 & 0,68 \\
13. & Suka Damai & 891 & 626 & 0,70 \\
14. & Suka Maju & 948,527 & 687 & 0,72 \\
\hline & Jumlah & $\mathbf{1 4 . 5 9 7}$ & $\mathbf{1 0 . 1 4 0}$ & $\mathbf{0 , 6 9}$ \\
\hline & Rata-rata & $1.042,64$ & 724,28 & \\
\hline
\end{tabular}

Sumber : Kantor Kecamatan Mestong, 2016 
Jurnal Media Agribisnis Vol. 3 No. 1 Tahun 2018 Hal 1 - 11

Media Komunikasi Hasil Penelitian Bidang Ilmu Agribisnis

ISSN print 2587-7027

ISSN online 2541-6898

Berdasarkan latar belakang diatas, maka penulis tertarik untuk melakukan penelitian yang berjudul " Faktor - Faktor Yang Mempengaruhi PenerimaanPetani Karet (Hevea Brasiliensis) DiDesa Baru Kecamatan Mestong Kabupaten Muaro Jambi”, dengan rumusan masalah sebagai berikut :

1. Bagaimana gambaran usahatani karet di Desa Baru Kecamatan Mestong Kabupaten Muaro Jambi ?

2. Bagaimana gambaran Produksi,Harga,Umur Tanaman, Tingkat Pendidikan Petani,Jenis Bibit, dan Teknik Penyadapankaret di Desa Baru Kecamatan Mestong Kabupaten Muaro Jambi ?

3. Bagaimanakah gambaran penerimaanusahatanikaretdiDesa Baru Kecamatan Mestong Kabupaten Muaro Jambi ?

4. Bagaimanakah pengaruh Produksi,Harga,Umur Tanaman, Tingkat Pendidikan Petani, Jenis Bibit, dan Teknik Penyadapan karet terhadap penerimaanpetanikaret di Desa Baru Kecamatan Mestong Kabupaten Muaro Jambi?

Adapun tujuan penelitian adalah untuk mengetahui :

1. Gambaran usahatani karet di Desa Baru Kecamatan Mestong Kabupaten Muaro Jambi.

2. Gambaran Produksi, Harga, UmurTanaman, Tingkat Pendidikan Petani,Jenis Bibit, dan Teknik Penyadapan karetdiDesa Baru Kecamatan Mestong Kabupaten Muaro Jambi.

3. Gambaran penerimaan usahatani karetdi Desa Baru Kecamatan Mestong Kabupaten Muaro Jambi.

4. Pengaruh Produksi,Harga,Umur Tanaman, Tingkat Pendidikan Petani,Jenis Bibit, dan Teknik Penyadapan karet terhadap penerimaan petani karet di Desa Baru Kecamatan Mestong Kabupaten Muaro Jambi.

\section{METODOLOGI PENELITIAN}

Ruang LingkupPenelitian ini membahas tentanggambaran kegiatan usahatani karet dan faktor-faktor yang mempengaruhi penerimaan usahatani karetdi Desa Baru Kecamatan Mestong Kabupaten Muaro Jambi, yang dilaksanakan pada bulan Juni 2017.

Penelitian ini menggunakan metode survey, menurut Silalahi (2010), bahwa survey adalah suatu usaha untuk mendapatkan dan mengumpulkan data dan informasi dari berbagai sumber.Jumlah 64 Rumah Tangga Petani (15\%) dari total populasi petani (427 RTP). Hal itu sesuai dengan pernyataanWinarno (2007), bahwa untuk pedoman umum dapat dikatakan bila populasi cukup homogen, terhadap populasi dibawah 100 dapat digunakan sampel sebesar $50 \%$ dan bila populasi diatas 100 dapat diambil sampel sebesar $15 \%$ dan juga sampel hendaknya diatas 30 0rang besarnya.

Sampel tersebut diambil dengan menggunakan metode simple random sampling atau secara acak. Hal itu sesuai dengan pernyataan Singarimbun (1982), bahwa penggunaan metode simple random samplingdapat memberikan peluang yang sama bagi anggota rumah tangga petani (RTP) populasi yang dipilih menjadi sampel. 
Jurnal Media Agribisnis Vol. 3 No. 1 Tahun 2018 Hal 1 - 11

Media Komunikasi Hasil Penelitian Bidang Ilmu Agribisnis

ISSN print 2587-7027

ISSN online 2541-6898

Untuk menganalisa data yang diperoleh dilapangan digunakan beberapa metode analisis sesuai dengan tujuan penelitian, yaitu sebagai berikut :

1. Penerimaan dianalisis dengan menggunakan rumus (Soekartawi, 1990) :

$\mathrm{TR}=\mathrm{HY}$. Y

$\mathrm{TR}=$ Total penerimaan usahatani $(\mathrm{Rp} / \mathrm{Sadap} / \mathrm{Ha})$

$\mathrm{HY}=$ Harga karetbokar $(\mathrm{Rp} / \mathrm{Kg})$

$\mathrm{Y}=$ Jumlah Produksi bokar $(\mathrm{Kg} / \mathrm{Sadap} / \mathrm{Ha})$

2. Untuk melihat pengaruhfaktor-faktor (produksi, harga, umur tanaman, tingkat pendidikan, jenis bibit, dan teknik penyadapan) dengan penerimaan petanikaret maka digunakan metode regresi linear berganda (Gujarati, 1999):

$\mathrm{Y}=\mathrm{b} 0+\mathrm{b} 1 \mathrm{X}_{1}+\mathrm{b} 2 \mathrm{X}_{2}+\mathrm{b} 3 \mathrm{X}_{3}+\mathrm{b} 4 \mathrm{X}_{4}+\mathrm{b} 5 \mathrm{D}_{5}+\mathrm{b} 6 \mathrm{D}_{6}+\mathrm{e}$

Tanda parameter yang diharapkan adalah $: \mathrm{b} 1, \mathrm{~b} 2, \mathrm{~b} 3, \mathrm{~b} 4>0$

Dimana :

$\mathrm{Y}=$ Penerimaan Petani Karet $(\mathrm{Rp} /$ Sadap $)$

$\mathrm{X}_{1} \quad=$ Produksi Karet $(\mathrm{Kg})$

$\mathrm{X}_{2} \quad=$ Harga karet $(\mathrm{Rp})$

$\mathrm{X}_{3} \quad=$ Umur Tanaman Karet (Tahun)

$\mathrm{X}_{4} \quad=$ Tingkat Pendidikan (Tahun)

$\mathrm{D}_{5} \quad=$ Jenis Bibit:D $=1$ untuk bibit unggul (yaitu apabila jumlah tanaman bibit unggul $\geq 50 \%$ dari seluruh tanaman karet yang ditanam) ; $\mathrm{D}=0$ untuk bibit bukan unggul (yaitu apabila jumlah tanaman bibit unggul $<50 \%$ dari seluruh tanaman karet yang ditanam).

$\mathrm{D}_{6} \quad=$ Teknik Penyadapan $: \mathrm{D}=1$ untuk penyadapan teknik spiral (apabila penyadapan dengan teknik spiral $\geq 50 \%$ dari seluruh teknik penyadapan tanaman karet) ; $\mathrm{D}=0$ untuk penyadapan selain spiral (apabila penyadapan dengan teknik spiral $<50 \%$ dari seluruh teknik penyadapan tanaman karet).

e $\quad=$ Faktor kesalahan / Eror

$\mathrm{b} 1, \mathrm{~b} 2, \mathrm{~b} 3, \mathrm{~b} 4=$ Parameter yang digunakan

Menurut Wibowo (2012), untuk ketepatan model regresi sampel dalam menafsir aktualnya dapat diukur dari goodness of fit nya. Goodness of fit dalam model regresi dapat diukur dari nilai analisis statistik $F$, nilai statistik $t$, dan koefisien determinasi.

Selanjutnya Kuncoro (2004), menyatakan koefisien determinasi $\left(\mathrm{R}^{2}\right)$ pada intinya digunakan untuk mengukur seberapa jauh kemampuan model dalam menerangkan variasi variabel terikatatau menguji seberapa besar variasi tak bebas dapat dijelaskan oleh variasi dari variabel bebas, dengan rumusnya sebagai berikut : $\mathrm{R}^{2}=\frac{b i \text { Eyiwi }}{\Sigma y i^{2}}$

Keterangan :

$\mathrm{R}^{2} \quad=$ Koefisien determinan

bi $\quad=$ Parameter variabel bebas ke-i

yi $\quad=$ Variabel terikat ke-i

$\mathrm{xi} \quad=$ Variabel bebas ke-i

$\sum \mathrm{yi}^{2}=$ Jumlah kuadrat variabel terikat ke-i 
Jurnal Media Agribisnis Vol. 3 No. 1 Tahun 2018 Hal 1 - 11

Media Komunikasi Hasil Penelitian Bidang Ilmu Agribisnis ISSN print 2587-7027

ISSN online 2541-6898

Nilai $\mathrm{R}^{2}$ mempunyai nilai 0-1. Makin besar $\mathrm{R}^{2}$ (mendekati 1) maka hasil estimasi akan semakin mendekati sebenarnya.

Dalam penelitian ini juga akan dilakukan uji $\mathrm{F}$ untuk mengetahui pengaruh secara bersama-sama variabel bebas terhadap variabel terikat (Hasan, 2006) metode yang digunakan adalah metode kuadrat terkecil dengan formula :

$F_{\text {hitung }}=\frac{\mathbb{R}^{2} / k}{\left(1-R^{2}\right)(n-k-1)}$

Dengan bentuk hipotesis statistik: $\quad$ Ho $: \mathrm{b} 0=\mathrm{b} 1=\mathrm{b} 2=\mathrm{b} 3=\mathrm{b} 4=\mathrm{b} 5=0$

$$
\text { Ha : b0 =b1 = b2=b3=b4=b5 } \neq 0
$$

Dimana bunyi hipotesis operasionalnya :

Ho :Tidak terdapat pengaruh faktor-faktor (produksi, harga, umur tanaman, tingkat pendidikan, jenis bibit, dan teknik penyadapan) secara simultan terhadap penerimaan petani karet di daerah penelitian.

Ha :Terdapat pengaruh faktor-faktor (produksi, harga, umur tanaman, tingkat pendidikan, jenis bibit, dan teknik penyadapan) secara simultan terhadap penerimaan petani karet di daerah penelitian.

Untuk mengambil keputusan, maka nilai $\mathrm{F}_{\text {hitung }}$ akan dibandingkan dengan nilai $\mathrm{F}_{\text {tabel }}$ dimana kaidah keputusannya adalah :

- Jika $\mathrm{F}_{\text {hitung }}>\mathrm{F} \alpha(\mathrm{k})(\mathrm{n}-\mathrm{k}-1)$, tolak Hoatau terima Ha.

- Jika $F_{\text {hitung }} \leq \mathrm{F} \alpha(\mathrm{k})(\mathrm{n}-\mathrm{k}-1)$, terima Ho atau tolak Ha.

Selanjutnya untuk menguji koefisien regresi secara parsial dari variabel independentnya digunakan Uji parsial atau Uji t. untuk menentukan nilai statistik $t_{\text {tabel }}$ ditentukan dengan tingkat signifikansi 5\% dengan derajat kebebasan $\mathrm{df}=(\mathrm{n}-$ $\mathrm{k}-1$ ) dimana $\mathrm{n}$ adalah jumlah observasi dan $\mathrm{k}$ adalah jumlah variabel. Rumus yang digunakan adalah ( Imam Ghozali, 2001), sebagai berikut :

$\mathrm{ti}=\frac{\beta t}{\operatorname{se}(\beta i)}$

dimana :

ti $=\mathrm{t}_{\text {hitung }}$

$\beta \mathrm{i}=$ Parameter dari variabel ke- $\mathrm{i}$

$\operatorname{Se}(\beta \mathrm{i})=$ Standar error

Untuk mengetahui keputusan nilai $t_{\text {hitung }}$ akan dibandingkan dengan $t_{\text {tabel }}$ dimana kaidah pengambilan keputusannya adalah :

- Jika $\left|t_{\text {hitung }}\right| \leq t \alpha / 2(n-k-1)$ terima Ho atau Ha ditolak.

- Jika $\left|t_{\text {hitung }}\right|>$ t $\alpha / 2(n-k-1)$ tolak Ho atau Ha diterima.

Dengan Hipotesis statistik: Ho : bi $=0$

$$
\mathrm{Ha}: \mathrm{bi} \neq 0
$$

Dimana bunyi hipotesis operarasionalnya :

Ho $=$ Tidak terdapat pengaruh variabel $\mathrm{Xi}$ terhadap variabel $\mathrm{Y}$, atau faktor produksi terhadap hasil penerimaan.

$\mathrm{Ha}=$ Terdapat pengaruh variabel $\mathrm{Xi}$ terhadap variabel $\mathrm{Y}$, atau faktor produksi terhadap hasil penerimaan. 
Jurnal Media Agribisnis Vol. 3 No. 1 Tahun 2018 Hal 1 - 11

Media Komunikasi Hasil Penelitian Bidang Ilmu Agribisnis

ISSN print 2587-7027

ISSN online 2541-6898

\section{HASIL DAN PEMBAHASAN}

\section{Identitas Petani Sampel}

a. Umur Petani Sampel

Distribusi frekuensi petani sampel berdasarkan umur dapat dilihat padaTabel 4berikut. Tabel 4 menunjukkan bahwa umur petani sampel berkisar antara 18 sampai dengan 66 tahun, dengan distribusi umur terbanyak ada pada kelas 4 yaitu umur 39 - 45 tahun yaitu 15 RTP $(23,44 \%)$, sedangkan yang paling sedikit ada pada kelas 1 dan 7 yaitu umur $18-24$ dan $60-66$ tahun yang masing-masingnya sebanyak 3 RTP (4,69\%). Dengan rata-rata umur petani sampel yaitu 41,02 tahun.

Tabel 4.Ditribusi Frekuensi Petani Sampel Berdasarkan Kelompok Umur di Daerah Penelitian Tahun 2017.

\begin{tabular}{lccc}
\hline No. & Umur Petani (Tahun) & Jumlah (RTP) & Persentase (\%) \\
\hline 1. & $18-24$ & 3 & 4,69 \\
2. & $25-31$ & 10 & 15,63 \\
3. & $32-38$ & 12 & 18,75 \\
4. & $39-45$ & 15 & 23,44 \\
5. & $46-52$ & 14 & 21,86 \\
6. & $53-59$ & 7 & 10,94 \\
7. & $60-66$ & 3 & 4,69 \\
\hline
\end{tabular}

Sumber : Olahan Data Primer Tahun 2017.

\section{b. Tingkat Pendidikan Petani Sampel}

Distribusi frekuensi petani sampel berdasarkan tingkat pendidikan dapat dilihat pada Tabel 5.Berdasarkan Tabel 5 dapat dilihat tingkat pendidikan petani sampel di daerah penelitian mayoritas berpendidikan Tamat Sekolah Dasar yaitu sebanyak 28 RTP $(43,75 \%)$, sedangkan yang minoritas adalah tidak tamat SMP yaitu sebanyak 1 RTP $(1,56 \%)$.

Tabel 5.Ditribusi Frekuensi Petani Sampel Berdasarkan Tingkat Pendidikan di Daerah Penelitian Tahun 2017.

\begin{tabular}{llcr}
\hline No. & Tingkat Pendidikan & Jumlah (RTP) & Persentase (\%) \\
\hline 1. & Tidak Tamat SD & 13 & 20,31 \\
2. & Tamat SD & 28 & 43,75 \\
3. & Tidak tamat SMP & 1 & 1,56 \\
4.. & Tamat SMP & 12 & 18,75 \\
5. & Tidak tamat SMA & 0 & 0 \\
6. & Tamat SMA & 8 & 12,50 \\
7. & D III & 2 & 3,13 \\
\hline & Jumlah & 64 & 100,00 \\
\hline
\end{tabular}

Sumber : Olahan Data Primer Tahun 2017.

\section{c. Jumlah Tanggungan Keluarga Petani Sampel}

Distribusi frekuensi petani sampel berdasarkan jumlah tanggungan keluarga dapat dilihat pada Tabel 6.Dari Tabel 6 dapat dijelaskan sebagian besar 
Jurnal Media Agribisnis Vol. 3 No. 1 Tahun 2018 Hal 1 - 11

Media Komunikasi Hasil Penelitian Bidang Ilmu Agribisnis

ISSN print 2587-7027

ISSN online 2541-6898

jumlah tanggungan keluarga petani sampel adalah 4 orang yaitu sebanyak 27 RTP $(42,19 \%)$, sedangkan untuk terendah pada kelas 6 dengan jumlah tanggungan keluarga 6 orang yaitu sebanyak 1 RTP (1,56 \%). Rata-rata jumlah tanggungan keluarga sebanyak 4 0rang.

Tabel 6.Distribusi Frekuensi Petani Sampel Berdasarkan Jumlah Tanggungan Keluarga di Daerah Penelitian tahun 2017.

\begin{tabular}{|c|c|c|c|}
\hline No. & $\begin{array}{c}\text { Jumlah Tangguangan Keluarga } \\
\text { (Orang) }\end{array}$ & Jumlah (RTP) & Persentase (\%) \\
\hline 1. & 1 & 6 & 9,38 \\
\hline 2 & 2 & 4 & 6,25 \\
\hline 3. & 3 & 15 & 23,44 \\
\hline 4 & 4 & 27 & 42,19 \\
\hline 5 & 5 & 11 & 17,19 \\
\hline 6 & 6 & 1 & 1,56 \\
\hline 7. & 7 & 0 & 0 \\
\hline \multicolumn{2}{|c|}{ Jumlah } & 64 & 100,00 \\
\hline
\end{tabular}

Sumber : Olahan Data Primer Tahun 2017

\section{d. Pengalaman Berusahatani Petani Sampel}

Distribusi frekuensi petani sampel berdasarkan pengalaman berusahatani dapat dilihat pada Tabel 7 berikut.

\begin{tabular}{lccc} 
Tabel & $\begin{array}{c}\text { 7.Distribusi Frekuensi } \\
\text { Berusahatanidi Daerah Penelitian Tahun 2017. }\end{array}$ & $\begin{array}{c}\text { Petani } \\
\text { Sampel }\end{array}$ & $\begin{array}{c}\text { Berdasarkan } \\
\text { Pengalaman }\end{array}$ \\
\hline No. & $\begin{array}{c}\text { Pengalaman Berusahatani } \\
\text { (Tahun) }\end{array}$ & Jumlah (RTP) & Persentase (\%) \\
\hline 1. & $2-9$ & 5 & 7,81 \\
2. & $10-17$ & 13 & 20,31 \\
3. & $18-25$ & 17 & 26,56 \\
4. & $26-33$ & 12 & 18,75 \\
5. & $34-41$ & 8 & 12,50 \\
6. & $42-49$ & 7 & 10,94 \\
7. & $50-57$ & 2 & 3,13 \\
\hline & Jumlah & 64 & 100,00 \\
\hline
\end{tabular}

Sumber : Olahan Data Primer Tahun 2017

Dari Tabel 7 dapat dijelaskan pengalaman berusahatani karet tertinggi sebanyak 17 RTP $(26,56 \%)$, dan pengalaman berusahatani terendah sebanyak 2 RTP $(3,13 \%)$. Rata-rata pengalaman petani didalam mengusahatani karet selama 25,98 tahun.

\section{Gambaran Usahatani Karet di Daerah Penelitian}

Tanaman karet rata-rata telah berumur 19,33 tahun dan kegiatan usahatani lebih ditekankan pada proses pemeliharaan seperti pengendalian gulma, pemupukan, dan penyadapan. Pada pengendalian gulma interval yang dilakukan 4 bulan sekali dengan penebasan menggunakan parang dan pemberian herbisida. 
Jurnal Media Agribisnis Vol. 3 No. 1 Tahun 2018 Hal 1 - 11

Media Komunikasi Hasil Penelitian Bidang Ilmu Agribisnis

ISSN print 2587-7027

ISSN online 2541-6898

Pengolahan lahan dimulai dengan cara pembabatan semak dan penebangan pohon besar menggunakan mesin. Jarak tanam karet petani 7 × 4 m, kemudian dibuat lubang tanam $40 \times$ x 40x $40 \mathrm{~cm}$. Kerapatan tanaman karet sebanyak 348.34 tanaman/Ha.

Penanaman dilalukan pada musim penghujan.Umur tanaman mulai berproduksi setelah tanaman berumur 5-6 tahun.Sedangkan proses pemanenan dilakukan 2 hari sekali rata-rata produksilateks $10,72 \mathrm{~kg} / \mathrm{Ha} /$ sadap. Pengumpulan bokar biasanya dilakukan setelah 3-4 kali penyadapan kemudian dikumpulkan di dalam bak.Dan dijual ke toke atau KUD dengan harga Rp. 7.457,81,-/Kg. Jadi bila dikonversikan penerimaan petani dalam 1 kali sadap bila rata-rata petani sampel menghasilkan 10,72 Kg/Habokar maka penghasilan per 1 kali sadap adalah Rp. $79.947,72,-/$ Ha. Dengan asumsi petani karet dapat menyadap pohon karetnya selama 14 kali, maka perbulannya petani sampel memperoleh penerimaan dari usaha tani karet adalah sebesar Rp. 1.119.268,08,-/ Ha/Bulan.

\section{Gambaran Variabel Bebas Yang Mempengaruhi Penerimaan Petani Karet}

Jumlah produksi karet berkisar antara $7-50 \mathrm{Kg} / \mathrm{Ha} / \mathrm{Sadap}$ denganrata-rata produksi karet adalah $10,72 \mathrm{Kg} / \mathrm{Ha} /$ Sadap.Harga karet berkisar antara $7.000-$ $7.800 \mathrm{Rp} / \mathrm{Kg}$ dengan rata-rata harga karet adalah 7.457,81 Rp/Kg. Umur tanaman karet berkisar antara 7 sampai dengan 41 tahun dengan rata-rata umur tanaman karet yaitu 19,33 tahun. Tingkat pendidikan petani karet paling rendah tidak tamat SD dan paling tinggi jenjang D3 dengan rata-rata tingkat pendidikan petani sampel adalah tidak tamat SMP atau 7,27 tahun. Petani karetmayoritasmenggunakan jenis bibit unggul yaitu sebanyak 41 RTP $(64,06 \%)$. Petani Karetmayoritas menerapkan teknik penyadapan bukan spiral yaitu sebanyak RTP 33 (51,56\%).

\section{Gambaran Penerimaan Petani Karet}

Penerimaan petani karet berkisar antara Rp. 37.000 - Rp. 190.016 /Ha/Sadap.Dengan rata-rata penerimaan petani Rp 87.453,95/Ha/Sadap.

\section{Analisis Faktor-Faktor Yang Mempengaruhi Penerimaan Karet}

Hasil analisis regresi linear berganda dengan bantuan komputer (Program SPSS Versi 16.0).Dari hasil analisis regresi linear berganda diperoleh nilai Adjusted R Square sebesar 0,630 ini menunjukkan koefisien determinasi penerimaan petani karet dapat dijelaskan $63,0 \%$ oleh variabel yang ada di dalam model (Produksi, Harga, Umur Tanaman, Tingkat Pendidikan, Jenis Bibit, dan Teknik Penyadapan karet) dan sisanya sebesar 37,0 \% dijelaskan oleh faktor lain yang tidak termasuk dalam perhitungan. 
Jurnal Media Agribisnis Vol. 3 No. 1 Tahun 2018 Hal 1 - 11

Media Komunikasi Hasil Penelitian Bidang Ilmu Agribisnis ISSN print 2587-7027

ISSN online 2541-6898

\begin{tabular}{|c|c|c|c|c|c|}
\hline \multicolumn{6}{|c|}{ Tabel 8. Hasil Analisis Regres } \\
\hline & Variabel & Koefisien Regres1 & t hitung & Sig & Ket. \\
\hline & Konstanta & -208.399 .103 & $-1,665$ & 0,101 & \\
\hline 1 . & $\left(\mathrm{X}_{1}\right)$ Produksi Karet & $3.232,854$ & 6,638 & 0,000 & \\
\hline 2. & $\left(\mathrm{X}_{2}\right)$ Harga karet & 28,567 & 1,715 & 0,092 & \\
\hline 3. & $\left(\mathrm{X}_{3}\right)$ Umur Tanaman & 121,334 & 0,034 & 0,764 & \\
\hline 4. & $\left(\mathrm{X}_{4}\right)$ Tingkat Pendidikan & $-1.299,144$ & $-1,088$ & 0,281 & \\
\hline 5. & $\left(D_{5}\right)$ Jenis Bibit & $25.479,568$ & 2,852 & 0,006 & \\
\hline 6. & $\left(D_{6}\right)$ Teknik Penyadapan & $16.415,420$ & 2,230 & 0,030 & \\
\hline & Ad'justed R Square & $=0,630$ & Sig F & $=0,000$ & \\
\hline & $\mathrm{F}_{\text {hitung }}$ & $=18,856$ & & & \\
\hline & $\mathrm{F}_{\text {tabel }}(6 ; 57)$ & $=2,515$ & & & \\
\hline & $\mathrm{T}_{\text {tabel }}(0,05 ; 57)$ & $=2,004$ & & & \\
\hline
\end{tabular}

Sumber : Hasil Analisis Olahan Data Primer Program SPSS, Tahun 2017.

Menurut Imam Ghozali (2001), uji statistik yang digunakan untuk menguji besarnya pengaruh dari seluruh variabel independen secara simultan terhadap variabel dependen digunakan Uji-F, $\mathrm{F}$ tabel tingkat signifikan digunakan $\alpha 5 \%$. Data analisis SPSS diperoleh nilai $\mathrm{F}_{\text {hitung }}=18,856>\mathrm{F}_{\text {tabel }} 2,515$ (Tabel 8). Secara simultan, Hipotesis yang menyatakan variabel-variabel bebas memberikan pengaruh secara nyata terhadap penerimaan petani karet, dapat diterima

Selanjutnya variabel-variabel independen yang berpengaruh secara parsial terhadap penerimaan petani karet adalah variabelProduksi, Harga, Umur Tanaman, Tingkat Pendidikan, Jenis Bibit, dan Teknik Penyadapan karet sebagai berikut :

Variabelproduksi karet $\left(\mathrm{X}_{1}\right)$, berpengaruh signifikan dilihat dari sig $\mathrm{t}=$ $0,000<\alpha=5 \%$, dan dilihat dari $\mathrm{t}_{\text {hitung }} 6,638>\mathrm{t}_{\text {tabel }} 2,004$ maka $\mathrm{H}_{0}$ ditolak dan $\mathrm{H}_{\mathrm{a}}$ diterima. Dengan demikian hipotesisnya yang berbunyi produksi karet berpengaruh terhadap penerimaan petani karet dapat diterima.

Variabel jenis bibit $\left(D_{5}\right)$, ternayata dari koefisien $\left(b_{5}\right)$ petani yangmenggunakan bibit unggul penerimaannya lebih tinggi yaitu sebesar Rp. $25.479,568$,- bila dibandingkan petani yang tidak menggunakan bibit bukan unggul.

Variabel teknik penyadapan $\left(D_{6}\right)$, ternayata dari koefisien $\left(b_{4}\right)$ petani menyadap dengan kategori secara spiral lebih tinggi yaitu sebesarRp. 16.415,420,bila dibandingkan dengan petani yang tidak menerapkan penyadapan kategori cara spiral.

Sedangkan variabel harga karet, umur tanaman, dan tingkat pendidikan, tidak mempengaruhi penerimaan petani secara nyata.

\section{KESIMPULAN}

Dari pembahasan diatas dapat disimpulkan:

1. Pengolahan lahan dengan cara pembabatan semak, dan penumbangan pohon besar kemudian dibuat jarak tanam $7 \times 4 \mathrm{~m}$, kemudian dibuat lubang tanam 40x40x40 cm,penanaman dilakukan pada saat musim penghujan, kemudian 
Jurnal Media Agribisnis Vol. 3 No. 1 Tahun 2018 Hal 1 - 11

Media Komunikasi Hasil Penelitian Bidang Ilmu Agribisnis

ISSN print 2587-7027

ISSN online 2541-6898

dilakukan perawatan sampai tanaman siap sadap \pm 5 tahun, penyadapan didaerah penelitian dilakukan 2 hari sekali dengan rata-rata produksi 10,72 $\mathrm{Kg} / \mathrm{Ha} / \mathrm{Sadap}$, dengan harga jual rata-rataRp 7.457,81/Ha, bokar kemudian dijual di toke atau KUD yang ada di daerah penelitian.

2. Rata-rata produksi karet $10,72 \mathrm{Kg} / \mathrm{Ha} / \mathrm{Sadap}$,rata-rata harga karet $\mathrm{Rp} 7.457,81$ /Kg.,rata-rata umur tanaman karet 19,33 tahun,dan rata-rata tingkat pendidikan tidak tamat SMP. Petani karetmayoritas menggunakan jenis bibit unggul yaitu sebanyak 41 RTP (64,06 \%). Petani Karetmayoritas menerapkan teknik penyadapan bukan spiral yaitu sebanyak RTP 33 (51,56 \%).

3. Rata-rata penerimaan usahatani adalah Rp.87.453,95/Ha/Sadap.

4. Hasil data analisis SPSS diperoleh $\mathrm{F}$ hitung $=18,856>\mathrm{F}$ tabel sebesar 2,515. secara simultan memberikan pengaruh secara nyata terhadap penerimaan petani.Secara parsial produksi karet, jenis bibit, dan teknik penyadapan merupakan faktor yang berpengaruh nyata terhadap penerimaan petani, sedangkan variabel lainnya tidak.

\section{DAFTAR PUSTAKA}

Dinas Perkebunan Provinsi Jambi. 2016. Jambi Dalam Angka. Dinas Perkebunan. Jambi

Ghozali, Imam. 2001. Aplikasi Analisis Multivariate Dengan Program SPSS. Badan Penelitian Universitas Diponegoro. Semarang.

Gujarati, Damodar. 1997. Ekonometrika Dasar. Erlangga. Jakarta

Hasan, M. Iqbal. 2006. Pokok-Pokok Materi Statistik (Statistik Deskriptif) Bumi Aksara. Jakarta

Kuncoro, M. 2004. Metode Riset Untuk Bisnis Dan Ekonomi. Universitas Gajah Mada. Jakarta

Silalahi, U. 2010. Metode Penelitian Sosial.PT. Refika Aditama. Bandung

Singarimbun. Masri, Sofian Effendi. 1982. Metode Survai/Editor. LP3ES. Jakarta

Soekartawi.1990. Prinsip Dasar Ekonomi Pertanian Teori dan Aplikasi.Raja Grafindo Persada. Jakarta

Wibowo. Larasati S. 2012. Analisis Efisiensi Alokatif Faktor-Faktor Produksi Dan Pendapatan Usahatani Padi (Oryza Sativa L.) Naskah Publikasi Jurnal

Winarno. 2007. Pedoman Umum Penarikan Sampel Populasi Cukup Homogen. Bina Aksara. Jakarta 